\title{
Н.Г. Костромина
}

\section{ПРОБЛЕМЫ ПЕРЕХОДА ОТ ТОТАЛИТАРИЗМА К ДЕМОКРАТИИ В РАБОТАХ ФРАНЦУЗСКОГО ПОЛИТОЛОГА И СОЦИОЛОГА РАЙМОНА АРОНА}

\begin{abstract}
Рассматривается взгляд известного французского политолога и социолога Раймона Арона на проблемы перехода от тоталитаризма к демократии. Выделены направления и схемы анализа тоталитарных режимов, выявлены их главные недостатки, анализируются основные труды Арона по данной проблематике. Показаны важность и дискуссионность представлений о либерализме. Анализ представленных схем либерализации тоталитарных режимов, проведенный Ароном, является комплексным и всесторонним.

Ключевые слова: Раймон Арон; демократия; тоталитаризм; проблемы перехода от тоталитаризма.
\end{abstract}

Раймон Арон - крупнейший французский ученый XX в. Библиография его работ обширна, а индекс ссылок на его исследования по сей день остается самым высоким. Трудно переоценить актуальность и значимость его работ. До сих пор выходят книги, посвященные Р. Арону [1].

Будучи социологом и политологом, Р. Арон размышлял о возможных методах правления в современных индустриальных обществах и считал, что самой главной опасностью, самым главным злом является тоталитарный режим. В его глазах сталинский режим был законченным, совершенным тоталитарным режимом. Сделать режим более тоталитарным было уже невозможно.

В ряде своих работ («Классовая борьба» [2], «Демократия и тоталитаризм» [3], «Цепные войны» [4], «Опиум интеллектуалов» [5], «Этапы развития социологической мысли» [6] и др.) ученый анализирует причины установления тоталитарных режимов. Красной нитью через все произведения Арона проходит мысль об опасности «сползания в тоталитаризм» конституционно-плюралистических режимов (демократий, подобных западным). Он указывает, что эта опасность вполне реальная, а не возможная альтернатива [7. С. 74]. Исходя из реальной угрозы ученый выявляет и дает подробное описание характерных черт различных режимов [3. С. 231]. Сопоставляя и сравнивая их между собой, он обнаруживает слабости каждого из них и размышляет об их возможном будущем.

Говоря о демократических режимах, он констатирует, что вероятность прихода к власти на различных этапах своего исторического развития однопартийных правительств весьма высока, но верит в то, что это лишь временный и необходимый шаг. Что же касается альтернатив тоталитарных режимов, то прогнозы ученого здесь не столь однозначны и оптимистичны, особенно в отношении советского режима.

Цель данной статьи - показать взгляд знаменитого французского ученого Р. Арона на проблемы перехода от тоталитаризма к демократии.

Раймон Арон считает, что существует всего два варианта развития событий: первый - насильственное свержение существующего режима извне, как это про- изошло с национал-социализмом, второй - изменения внутри самого режима, не исключая радикальные, такие как революции и перевороты.

Что касается судьбы национал-социализма, по мнению ученого, она была предрешена, когда «в 1939 г. государство ввязалось в военную авантюру». При этом он отмечает, что национал-социалистскому режиму было отпущено всего лишь шесть лет мирной жизни и, если бы ему было дано больше времени, неизвестно, как бы он развивался дальше. Однозначный ответ получить никогда не удастся [Там же. С. 114]. «Мы никогда не узнаем, каким оказалось бы второе или третье поколение гитлеровцев, какими бы стали Германия и Европа в результате победы Третьего рейха» [8. С. 226].

Советский режим, история которого охватывает множество этапов, представляет широкое поле для размышлений. Р. Арон подробно исследует разные периоды истории русской большевистской партии и выделяет пять этапов. Первый прошел до взятия власти. Второй этап последовал после взятия власти и при жизни Ленина, практика партии стала другой. Третий этап - период борьбы между преемниками, с 1923 по 1930 г. Четвертый этап характеризуется всемогуществом Сталина: между 1930 и 1953 гг. И пятый этап, когда разворачивается борьба между его преемниками и утверждается новый стиль в жизни партии, - с 1953 по 1965 г. На пятом этапе, отмечает ученый, происходят существенные изменения. «Теперь не может быть и речи о сосредоточении власти в руках одного человека» [3. С. 114]. Тем не менее соперничество между преемниками напоминает борьбу периода 1923-1930 гг., хотя они и не преступают «кровавую черту»: противников устраняют, но - политически, а не физически. Решения по-прежнему принимаются на высшем уровне, но, пожалуй, не единолично, а группой. Это называется коллегиальным руководством. Чтобы нанести поражение какой-либо группе, против нее всякий раз образуют большинство. Таким образом, власть пока продолжает оставаться на вершине, а не в массах, однако количество тех, кто влияет на принятие решений, увеличилось. По мнению Р. Арона, на пятом этапе Советский Союз вышел из экстремальной фазы [8. C. 201]. 
Затем Р. Арон задается вопросами: Что же дальше? Какова судьба советского режима? Произойдет ли его демократизация? Каковы возможные проблемы трансформации данного режима? Ответы на эти вопросы не могут быть однозначными. Применительно к советскому режиму, считает Р. Арон, осмысление должно быть комплексным. Разнообразные аспекты режима не могут быть объяснены одной отдельно взятой причиной.

В ходе исследования Арон обнаруживает в обществе советского типа некоторые черты бюрократических империй: единственным управляющим коллективным трудом является государство; единственный привилегированный класс - государственная бюрократия, есть и противоречия, но без классовой борьбы в западном понимании [3. С. 121]. В работе «Классовая борьба» он отмечает, что классовая борьба в западном понимании подразумевает не только разнообразие социальных групп, но и способность этих групп к самоорганизации, возможность выдвигать и отстаивать свои требования. Также в обществах этого типа уровень доходов и образ жизни отличаются по группам, но ни одна из них не может быть независимой, ни одна не сможет противопоставить себя остальным. Этот вид социальной структуры, считает исследователь, нельзя считать переходным, так как он является неизбежным следствием отмены всей частной собственности и всякого рыночного механизма. В результате таких коренных реорганизаций руководитель предприятия является всего лишь государственным служащим, а любой гражданин получит право на богатство и власть, только если будет принадлежать к государственному привилегированному классу [2. Р. 10.]. Подобное описание будет присутствовать в работах специалистов по истории коммунистического режима [9].

Популярную среди социологов идею о связи экономического прогресса и демократии [10] Арон также считает сомнительной, хотя допускает, что с достижением высокого уровня развития производительных сил режим станет менее безжалостным к тем, кто не согласен с официальной линией. По его мнению, экономический прогресс не может автоматически привести к созданию демократического режима, этого недостаточно.

Проблема заключается в своеобразии самого советского режима. Наблюдается три аспекта, определяющих оригинальность коммунистического режима. Первый заключается в обладании полицейскими и пропагандистскими институтами, которые отсутствовали во всех деспотических режимах прошлого. Второй показывает наличие странного сочетания авторитарной бюрократии и стремления построить социализм. Новизна бюрократического управления страной заключена в его цели - ускоренном развитии средств производства. Третий аспект указывает на подчиненность бюрократического аппарата партии, что имеет революционный смысл. Отмеченная специфика коммунистического режима «позволяет сделать несколько замечаний о его дальнейшей судьбе». Р. Арон пишет: «Мой долг - остановиться на возможности разложения... режима во главе с монополизировавшей власть партией. Разложение такого режима означало бы его десоветизацию. Объективно говоря, разложение - это отказ от ряда присущих режиму функций» [3. С. 124].

Ученый считает, что самый простой способ проанализировать указанную проблему - противопоставить оптимистическую и пессимистическую версии марксизма.

Оптимистическую версию сформулировал Исаак Дойчер, считая связь между экономическим развитием и прискорбными явлениями советского режима неразрывной [11]. Все идеологические перегибы, террор, однопартийное руководство, политические процессы объяснялись необходимостью индустриализации. Таким образом, как только закончится этот этап, постепенно иссякнут и все патологические черты $[12,13]$.

Пессимистическая версия основана на концепции азиатского способа производства, согласно которой полное обюрокрачивание жизни советского режима является не патологическим явлением, как считают оптимисты, а типичным для бюрократического абсолютизма, однопартийности, идеологической ортодоксальности.

Раймон Арон отмечает, что между этими версиями существует множество промежуточных вариантов. Соответственно, встает вопрос: какие черты советского режима обоснованы нуждами индустриализации, а какие объясняются принципиальной структурой советского режима? [14. С. 447]. Для ответа на этот вопрос ученый дает обзор основных преобразований советского режима после смерти Сталина. Во-первых, важные изменения произошли в области личных свобод граждан: прекратился террор, наступила «оттепель», общий характер режима по сравнению с предыдущим (до 1953 г.) изменился. Но, по мнению ученого, «эти глубокие, важнейшие перемены» - пока не революция [3. С. 125]. Десталинизация нередко осуществляется сталинскими методами. Во-вторых, у полиции нет прежней роли, но она подвластна правительству и подчиняется его решениям. В-третьих, грандиозных чисток больше не проводится, но стабильно проходит какое-то подобие чистки. По-прежнему быстро происходит «циркуляция элиты», что указывает на продолжение борьбы фракций и лидеров. Четвертое, главное, руководящая роль в экономике, государственных делах и духовной жизни по-прежнему принадлежит партии. Главные черты режима остались неизменными. Произошли перемены и в экономической области. Повысился уровень жизни населения, стали производить больше товаров широкого потребления, более гибкими стали методы руководства. Появились материальные поощрения работников для увеличения производительности труда [14. С. 447].

Арон с грустью констатирует: «Я прихожу к следующему выводу: до сих пор наблюдались изменения внутри режима, но не изменения самого политикоэкономического режима, который проводит различные реформы, не затрагивая основ. Какие же перемены должны произойти, чтобы можно было говорить об изменении сути режима?» [3. С. 126]. Важнейшими чертами советского режима французский ученый считает: 1) однопартийность и сохранение идеологической ортодоксальности, единственным выразителем которой 
является партия; 2) централизованное планирование, которое осуществляет бюрократия; 3) бюрократическую иерархию, которая является основной причиной неравенства в обществе. Также стоит отметить отсутствие априори любых автономных сил, кроме государственных. По сравнению с любым западным обществом, классовым по своей сути, группы коммунистического общества являются составной частью бюрократической, государственной иерархии. Готовности изменить (разрушить) эту структуру у наследников Сталина нет. Советизм по-прежнему жив, но сталинизма уже нет [8. С. 243].

Далее Р. Арон рассматривает отдаленные перспективы преображения советского режима. Он детально останавливается на трех отвлеченных схемах, предлагаемых учеными, верящими в преображение советского режима.

Первая схема, оптимистическая, касается возможности преображения самой системы. Она основана на связи экономического положения и жестокости советского режима и предполагает, что вместе с повышением уровня жизни населения будет расти и его культурный уровень, а это, в свою очередь, приведет к либерализации самого режима. Но, предостерегает исследователь, данная неомарксистская схема основана на представлении о прямой взаимной связи между уровнем жизни и культуры, с одной стороны, и демократическими (либеральными) формами государственных институтов - с другой. Проблема заключается в том, что наличие этой взаимосвязи не доказано. Примером является печальный опыт нацистской Германии. Уровень жизни и культуры населения был высоким, но это не помешало принять режим с партией, монополизировавшей власть, и «поразительно тупоумной идеологией» [5. Р. 12]. Опыт однопартийных режимов и демократических стран свидетельствует, что даже просвещенные люди легко принимают более или менее нелепые идеологические построения. В определенных обстоятельствах кто угодно готов уверовать во что угодно [5. Р. 10]. Если допустить, что русские люди будут все меньше придерживаться своей идеологии, это не будет обозначать, что идеология перестанет играть важнейшую роль. История показывает, что множество официальных доктрин после утраты веры в эти доктрины десятилетиями и даже столетиями сохранялось как средство управления. Наконец, считает ученый, невозможно утверждать заранее, что развитое индустриальное общество обязательно приведет к социально-политическому режиму, подобному западному, так как режим бюрократической иерархии, авторитарного планирования полностью совместим с развитым индустриальным обществом [8. С. 687].

Второе оптимистическое суждение о будущем советского режима основано на схеме метаморфозы революций. У всех революций есть общая черта - они не бесконечны. Постепенно революционный энтузиазм иссякает, происходит возврат к серым будням. Коммунисты Советского Союза, считает Арон, в итоге тоже будут вынуждены смириться с устоявшимся порядком вещей. Эти рассуждения базируются на идеях постепенного отмирания революционной веры либо постепенного становления какого-то привилегированного класса. Например, Джилас обвинял своих прежних соратников в обуржуазивании, которое в глазах революционера свидетельствовало о разложении революции. Для социолога же этот процесс представлялся необходимым возвратом к норме существования. Поэтому Р. Арону данная схема представляется убедительной, но вряд ли она приведет к потрясению режима. Могут исчезнуть некоторые явления, такие как пристрастие к идеологическому террору, но единовластие партии, идеологическая правоверность и бюрократический абсолютизм останутся неизменными. Режим в своих структурных чертах может просуществовать еще длительное время [3. С. 128].

Третья схема преображения режима - рационализация. Она базируется на представлении о Советском Союзе американского социолога Б. Мура, который увидел в советском режиме «сочетание трех начал»традиционного, рационального и террористического. Предполагается, что рано или поздно режим станет все более традиционным и рациональным [15. С. 56]. Традиционным в смысле укоренения определенных привычек, рациональным потому, что советские руководители постараются изготавливать как можно больше продукции и по возможности дешевле, все меньше уделяя внимания идеологии, следовательно, все реже используя крайние средства. Анализируя эту схему, Арон допускает, что в длительной перспективе экономические взгляды станут преобладающими. Будущие руководители советской экономики будут все больше озабочены производительностью труда, чем теорией. Но тогда встает вопрос о духовной свободе и многопартийности: являются ли они рациональными феноменами? Рационализировать экономический и политический режим, устранить такие патологические излишества, как строгое планирование или чистки, вполне возможно, но установить режим, подобный западным, совершенно другое дело. Таким образом, считать рационализацию советского режима явлением, сопровождающим демократизацию, значит как минимум соглашаться со спорным утверждением о том, что единственным рациональным решением для экономики, нацеленной на развитие промышленности, является многопартийный режим [14. С. 448].

Подводя итоги анализа трех схем, Арон отмечает, что можно принять часть аргументов, приведенных оптимистами. Вполне можно допустить, что рациональнее станет управление хозяйством, условия жизни граждан улучшатся, наступит идеологическая разрядка и т.д. Но остается одно сомнение. Связано оно с тем, что преображения никак нельзя считать несовместимыми с основами самого режима. Первое - это единовластие партии, обстоятельство, которое исключает либо по крайней мере затрудняет «проведение курса на конституционность борьбы за власть, идеологический плюрализм». Второе - бюрократический абсолютизм, при котором практически невозможно создать центры независимых сил. Сохранить основы чрезвычайно важно. Это отвечает сущности режима. Последнее и, по мнению Арона, важнейшее: в подобном режиме решающую роль играет партиец, аппаратчик. 
Оптимистические предсказания относительно будущего советского режима сформированы часто на уверенности в том, что специалисты, хозяйственники обязательно должны одержать победу над аппаратчиками. Тем не менее в борьбе между преемниками Сталина победил партиец [3. С. 129].

При таком режиме люди, обладающие привилегиями, в отличие от западных партий на фракции не делятся. Невозможно представить, что имеется партия специалистов, которая выступает против партии идеологов, или военных, или полицейских. Большинство специалистов являются членами партии. Партийцы являются важной составляющей основной части политического персонала, который по большому счету определяет важнейшие черты режима. На Западе есть профессиональные политики, правительственные проблемы там определенным образом улаживаются политическими деятелями, которые используют свои методы прихода к власти и собственные способы проверки преданности граждан. В советском государстве такими политическими деятелями являются аппаратчики [Там же]. Политики решают многие сходные проблемы, некоторые из них являются универсальными, например как удержать власть в своих руках, как управлять страной, как урегулировать конфликт, но решения каждый принимает разные. Политики способны конституировать единую партию, в которой будет особый характер соперничества. Однопартийность обладает значительными преимуществами. Идеология постоянно будет являться оправданием для партии, и провозглашать законность учрежденной власти и правомерность деяний правителей, а партия может не признавать официально наличие конфликтов. Такое общество принципиально однородно. Поэтому вполне объяснимо, что, привыкнув к однопартийному режиму, политики во что бы то ни стало стараются сохранить эту структуру. Предполагаемые перемены, сопутствующие развитию промышленности и повышению уровня жизни населения, не могут привести к ликвидации однопартийности и идеологии, так же как и не исчезнет присущая обществу и государству бюрократическая иерархия. Подобной позиции придерживаются и другие ученые [16].

Следующая гипотеза преображения советского режима, которую рассматривает Р. Арон, - гипотеза революции. Ученый предположил, что раз случаются революции против плюралистических режимов, то вполне вероятны революции и против однопартийных режимов. Примером являются революции в Восточной Европе против режимов, «точнее, псевдорежимов с единовластной партией». Раймон Арон определяет их так, потому что и в Польше, и в Венгрии не было главного: национального характера самого режима. Поэтому в этих странах не мог утвердиться и стать долговечным режим без поддержки советского государства [3. С. 130].

Для того, чтобы произошла революция в режиме с единовластной партией, необходимо, чтобы сначала произошел раскол в правящей верхушке. До тех пор пока все политики и бюрократия будут едины, сложно предположить бунт управляемых. Проблема заключается и в том, что сложно предположить появление это- го желания у русского населения. Установление режима не было результатом свободного выбора, так же как и нет в Советском Союзе традиции вверять свою судьбу выборам [17. С. 195]. Управляемые в советском государстве убеждены в том, что вряд ли кто будет интересоваться их отношением к государству. Позже подобные выводы сделали и другие авторы [18].

Арон, анализируя «либерализацию» и ее пределы, которые возможны в режимах советского типа, в 1981 г. писал: «Пределы были весьма ограниченными. Я был, вероятно, скорее слишком оптимистичным относительно возможностей преобразования советского режима. Но в основном то, что я говорил, остается правильным и в настоящее время» [19. С. 286]. К сожалению, отмечает исследователь, либерализация однопартийных режимов «не предусмотрена заранее в книге Истории».

Рассмотрение различных схем привело ученого к двум основным положениям. Разнообразные периоды экономического роста в некоторой степени благоприятно влияют на тот или иной режим, но, если забыть об абсолютном изобилии, ничто не доказывает, что в индустриальных обществах возможен только один тип политической надстройки. Можно представить себе высокоразвитую индустриальную цивилизацию с разнообразными режимами.

Нынешний мир явно не согласуется ни с одной упрощенной схемой. У индустриальных обществ есть выбор между либеральной демократией и демократией тиранической. Так, на основе противопоставления друг другу двух типов современных режимов происходит возвращение к альтернативе, сформулированной Токвилем [6. С. 255-266].

Раймон Арон рассмотрел различные типы режимов и перспективы их развития. Исследования автора построены на уверенности в том, что наиболее приемлемой и перспективной формой существования большинства режимов является конституционно-плюралистическая. История представляет разные варианты и сочетания и доказывает состоятельность данных представлений. Поэтому будущее тоталитарных режимов зависит от многих факторов. Не исключено, что такая форма правления при желании может продержаться очень долго, от нескольких десятилетий до столетий. Сосредоточив внимание на варианте, предусматривающем в итоге изменение формы правления, можно сказать, что Арон выделил всего два возможных пути: насильственное устранение извне и внутреннее преобразование режима. Подробно остановившись на рассмотрении схем внутреннего преобразования режима, ученый обозначил ряд проблем в экономике и политике, с которыми он неизбежно столкнется. Но самой главной проблемой, по его мнению, является проблема нежелания властвующей элиты изменить суть самого режима.

Своими исследованиями о проблемах возможного перехода от тоталитаризма к демократии Раймон Арон предвосхитил события. В 70-90-е гг. ХХ в. резко возрос интерес к проблемам перехода от различных форм диктатуры (авторитаризма и тоталитаризма) к демократии [20-22]. Вызвано это было процессами, происходившими в ряде стран в данный период. 
Таким образом, французский социолог и политолог сделал солидный вклад в изучение различных типов режимов, рассмотрел ряд теорий и схем преобразования тоталитарных режимов, обозначил главные проблемы выхода из тоталитаризма. Исследования Раймона Арона представляют большую ценность для мировой науки.

\section{ЛИТЕРАТУРА}

1. The Companion to Raymond Aron / J. Colen, E. Dutartre-Michaut (eds). Basingstoke : Palgrave Macmillan, 2015. .

2. Aron R. La Lutte de classes. Paris : Gallimard, 1966.

3. Арон Р. Демократия и тоталитаризм / пер. с франц. Г.И. Семенова. М. : Текст, 1993.

4. Aron R. Les Guerres en chain. Paris : Gallimard, 1951.

5. Aron, R. The Opium of the Intellectuals. New York : Doubleday \& Company, Inc., 1957.

6. Арон Р. Этапы развития социологической мысли / общ. ред. и предисл. П.С. Гуревича. М. : Прогресс-Политика, 1992.

7. Костромина Н.Г. Теория и практика тоталитаризма в оценке французской исторической и политической мысли в ХХ веке. Томск : Изд-во Том. гос. пед. ун-та, 2008.

8. Арон Р. История XX века. Антология. М. : Ладомир, 2007.

9. Верт Н. История советского государства. 1900-1991. М., 1992.

10. Сартори Дж. Вертикальная демократия // Полис. 1993. № 2. С. 80-89.

11. Deutscher I. Russia After Stalin. London, 1953.

12. Deutscher I. Russia, What Next? New York : Oxford University Press, 1953.

13. Deutscher I. Russia in transition, and other essays. New York : Coward-McCann, Inc., 1957.

14. Арон Р. Мемуары: 50 лет размышлений о политике. М., 2002.

15. Moore B., jr. Social origins of dictatorship and democracy. Lord and Peasant in the Making of the Modern World. Boston : Beacon Press, 1966.

16. Пшеворский А. Переходы к демократии // Путь. 1993. № 3.

17. Aron R. Essai sur les libertes. Paris : Calmann-Levy, 1976. URL: http://www.civisbook.ru/files/File/1996-1-Aron.pdf

18. Зиновьев А. Коммунизм как реальность. М., 1994.

19. Арон Р. Пристрастный зритель / пер. с франц. под ред. Б.М. Скуратова. М. : Праксис, 2006

20. Гонсалес Ф. Создать в обществе основу для согласия и перемен // Свободная мысль. 1995. № 15.

21. Растоу Д.А. Переходы к демократии: попытка динамической модели // Полис. 1996. № 5. С. 5-15.

22. Шумпетер Й. Капитализм, социализм и демократия. URL: https://royallib.com/book/shumpeter_yozef/kapitalizm_sotsializm_i_demokratiya.html

\section{Kostromina Nadezhda G. Kemerovo State University. (Kemerovo, Russia). E-mail: Klio73@mail.ru}

PROBLEMS OF TRANSITION FROM TOTALITARIANISM TO DEMOCRACY IN THE WORKS OF THE FRENCH POLITICAL SCIENTIST AND SOCIOLOGIST RAYMOND ARON

Keywords: Raymond Aron; democracy; totalitarianism; problems of transition from totalitarianism.

Many well-known scientists studied totalitarianism. The result of their research was the emergence of a number of global theories, including the creation of a theory of totalitarianism. Within the framework of these theories has been given the typology and characteristics of totalitarian regimes; the origins, formation and practice of one-party regimes have been studied in detail. Most of the researches were limited to the study of varieties of the totalitarian regime, a comparative analysis of modes within a single theory. Raymond Aron was one of the few scientists who studied not only the theory and practice in detail, and as one of the pioneers of the theory of totalitarianism gave a description of these regimes, but also thought about the future of the existing regimes.

The purpose of the article is to show the view of the famous French sociologist and political scientist Raymond Aron on the problems of transition from totalitarianism to democracy. The sources of research were the works of the French scientist, devoted to the analysis of known regimes. The brightest of them are "Democracy and Totalitarianism", "Class Struggle", "History of the Twentieth Century", "Memoirs", "Stages of Development of Sociological Thought", "Opium of Intellectuals", "Biased Viewer".

A red thread through all the works of Aaron is the idea of the danger of "slipping into totalitarian" constitutional-pluralistic regimes (like the Western democracies). He admits that this danger is very real, and not a possible alternative. Based on a real threat, the scientist identifies and gives a detailed description of the characteristic features of various modes. Matching and comparing them with each other, he finds the weaknesses of each of them. And he reflects on the possible future of each of them. Speaking about democratic regimes, he states that the likelihood of coming to power, at various stages of its historical development, of one-party governments is very high, but believes that this is only a temporary and necessary step. As for the alternatives of totalitarian regimes, the scientist's forecasts here are not so unambiguous and optimistic. Especially in relation to the Soviet regime.

R. Aron believes that there are only two versions of the development of events. The first is the forcible overthrow of the existing regime from the outside, as happened with the national-socialist and the second is the changes within the regime itself, not excluding radical, such as revolutions and coups.

In this way, the French sociologist and political scientist made a solid contribution to the study of various types of regimes, considered various theories and schemes for the transformation of totalitarian regimes. He outlined the main problems of getting out of totalitarianism. Raymond Aron's study represent a significant value to the world of science.

\section{REFERENCES}

1. Colen, J. \& Dutartre-Michaut, E. (eds) The Companion to Raymond Aron. Basingstoke: Palgrave Macmillan.

2. Aron, R. (1966) La Lutte de classes [Class Struggle]. Paris: Gallimard.

3. Aron, R. (1993) Demokratiya i totalitarizm [Democracy and totalitarianism]. Translated from French by G.I. Semenov. Moscow: Tekst.

4. Aron, R. (1951) Les Guerres en chain [The Chain Wars]. Paris: Gallimard.

5. Aron, R. (1957) The Opium of the Intellectuals. New York: Doubleday \& Company, Inc.

6. Aron, R. (1992) Etapy razvitiya sotsiologicheskoy mysli [Stages of development of sociological thought]. Translated from English. Moscow: ProgressPolitika.

7. Kostromina, N.G. (2008) Teoriya i praktika totalitarizma $v$ otsenke frantsuzskoy istoricheskoy $i$ politicheskoy mysli $v$ XX veke [The theory and practice of totalitarianism in the assessment of French historical and political thought in the 20th century]. Tomsk: Tomsk State Pedagogical University.

8. Aron, R. (2007) Istoriya XX veka. Antologiya [History of the twentieth century]. Translated from English by L.G. Larionova. Moscow: Ladomir.

9. Werth, N. (1992) Istoriya sovetskogo gosudarstva. 1900-1991 [History of the Soviet state. 1900-1991]. Translated from French. Moscow: Progress. 
10. Sartori, J. (1993) Vertikal'naya demokratiya [Vertical democracy]. Polis. 2. pp. 80-89.

11. Deutscher, I. (1953) Russia After Stalin. London: Hamish Hamilton.

12. Deutscher, I. (1953) Russia, What Next? New York: Oxford University Press.

13. Deutscher, I. (1957) Russia in transition, and other essays. New York: Coward- McCann, Inc.

14. Aron, R. (2002) Memuary: 50 let razmyshleniy o politike [Memoirs: 50 years of thinking about politics]. Moscow: Ladomir.

15. Moore, B. Jun. (1966) Social origins of dictatorship and democracy. Lord and Peasant in the Making of the Modern World. Boston: Beacon Press

16. Pshevorskiy, A. (1993) Perekhody k demokratii [Transitions to Democracy]. Put'. 3.

17. Aron, R. (1976) Essai sur les libertes [Essay on Liberty]. Paris: Calmann-Levy. [Online] Available from: http://www.civisbook.ru/files/File/1996-1Aron.pdf.

18. Zinovyev, A. (1994) Kommunizm kak real'nost' [Communism as a reality]. Moscow: Tsentrpoligraf.

19. Aron, R. (2006) Pristrastnyy zritel' [Biased Viewer]. Transalted from French. Moscow: Praksis.

20. Gonsales, F. (1995) Sozdat' v obshchestve osnovu dlya soglasiya i peremen [To create a basis for agreement and change in society]. Svobodnaya mysl'. 15.

21. Rastou, D.A. (1996) Perekhody k demokratii: popytka dinamicheskoy modeli [Transitions to democracy: an attempt at a dynamic model]. Polis. 5. pp. 5-15.

22. Shumpeter, J. (n.d.) Kapitalizm, sotsializm i demokratiya [Capitalism, socialism and democracy]. https://royallib.com/book/shumpeter_ yozef/kapitalizm_sotsializm_i_demokratiya.html. 